\title{
The Effect of Aerobic Exercise on Depression and Academic Performance of University Students with Autism Spectrum Disorder
}

\author{
Naomi Clark, ${ }^{1}$ Susan Ross, ${ }^{1}$ Julie Reneau, ${ }^{1}$ \\ Julia Matzenbacher dos Santos ${ }^{2}$
}

\begin{abstract}
Depression is the most common Autism Spectrum Disorder (ASD) comorbidity, and have been shown to relate to significantly poorer life functioning. ASD can also result in social isolation, debilitating moods, and stereotypical behaviors, which can negative effect academic performance. Young adults with ASD are less likely to enroll in college than are people with other types of disabilities. The aim of this study is to examine the effect of an exercise program on depression and academic performance within university students with ASD. University students with ASD participated in a circuit training exercise protocol for three weeks. Depressive mood states were measured pre-and-post exercise session by a self-report questionnaire, whereas, academic performance was evaluated pre-and-post study by academic performance questionnaire. Participants mood improved after a bout of exercise on the first training day, however it was not observed on the following weeks. There were no changes in academic performance. Exercise might be effective on academic performance when the protocol is performed at longer rate. However, a bout of exercise prior to class could ameliorate ASD university student performance during class by the improvement of depression.
\end{abstract}

Keywords: Autism Spectrum Disorder (ASD); aerobic exercise; mood; depression; academic performance; university students.

\section{O EFEITO DO EXERCíCIO AERÓBICO NA DEPRESSÃO E NO DESEMPENHO} ACADÊMICO DE ESTUDANTES UNIVERSITÁRIOS COM AUTISMO

\section{RESUMO}

A depressão é a comorbidade mais comum do Transtorno do Espectro do Autista (TEA) e demonstrou estar relacionada negativamente à execução de atividades diárias. O TEA também pode resultar em isolamento social, humor debilitante e comportamentos estereotipados, que podem afetar negativamente o desempenho acadêmico. Jovens adultos com TEA são menos propensos a ingressar na faculdade do que as pessoas com outros tipos de deficiência O objetivo deste estudo é examinar o efeito de um programa de exercícios sobre depressão e desempenho acadêmico em estudantes universitários com TEA. Estudantes universitários com TEA participaram de um protocolo de exercícios físicos aeróbicos por três semanas. As modificações de humor relacionadas com depressão foram medidas antes e após a sessão de exercícios por um questionário de autorrelato, enquanto o desempenho acadêmico foi avaliado antes e após um protocolo de exercícios físico pelo professor. O humor dos participantes melhorou após uma sessão de exercício no primeiro dia de protocolo, no entanto isso não foi observado nas semanas seguintes. Não houve mudanças no desempenho acadêmico. O exercício pode ser eficaz no desempenho acadêmico quando o protocolo é realizado em um período maior. Uma única sessão de exercícios antes da aula, no entanto, pode ajudar no desempenho dos estudantes universitários com TEA durante as aulas, com a melhora do humor.

Palavras-chave: Transtorno do Espectro do Autista (TEA); exercício aeróbico; humor; depressão; desempenho acadêmico; estudantes universitários.

RECEBIDO EM: 6/8/2020

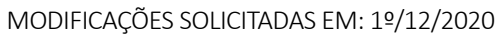

ACEITO EM: 10/12/2020

\footnotetext{
${ }^{1}$ College of Education, Health and Human Performance, Fairmont State University. Fairmont/WV, USA.

2 Autora correspondente. College of Education, Health and Human Performance, Fairmont State University. Locust Avenue, Fairmont/WV, USA. http://lattes.cnpq.br/8518388745447251. https://orcid.org/0000-0003-2758-9452. julia.dossantos@ fairmontstate.edu
} 


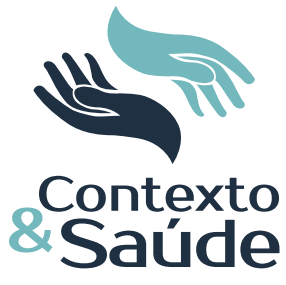

\section{INTRODUCTION}

Autism is considered the most common neurodevelopmental disability, estimated to affect one in 68 children, and $1 \%$ of the world population (BAIO et al., 2014). Autism spectrum disorders (ASD) are defined by delays in social communication, emotional reciprocity, and restrictive, repetitive, patterns of behavior or interests that can persist throughout life (BAIO et al., 2014). Individuals with ASD may also experience deficits in movement abilities, such as balance, joint flexibility, coordination, and movement speed which can result in reduced physical activity levels (LAVELLE et al., 2013). ASD can also result in social isolation, debilitating moods, and stereotypical behaviors, which can negatively effect academic performance. Young adults with ASD are less likely to enroll in college than are people with other types of disabilities (WEI et al., 2013). According to Lavelle et al. (2014), it costs on average more than $\$ 8,600$ per year to educate a student with ASD compared to a student without disorder (LAVELLE et al., 2014).

Young adults with ASD are shown to have an increased risk of poor health and depressive mood symptoms due to sensory and motor skill deficits, communication difficulties, lack of interests, and sedentary lifestyles (SPRATT et al., 2018). Depressive mood disorder is considered the most common ASD psychiatric comorbidity (STRANG et al., 2012). Rates of depressive mood disorder are approximately seven times higher in adolescents with ASD compared to adolescence without, and reports of depressed mood have been shown as high as 50\% (SPRATT et al., 2018). Depressive mood symptoms may exacerbate core ASD characteristics, resulting in sleep disturbances, aggression, self-injurious behavior, obsessive behavior and poor health and life functioning (STERLING et al., 2007).

Depression has an enormous negative impact on the overall health of depressed individuals, including physical health. Individuals with depressed moods have been shown to exhibit poor health behaviors and tend to be sedentary (PAPASAVVAS et al., 2016; SCHUCH et al. 2017), and overweight (MANNAN et al., 2016). While exercise interventions to improve depression and mood swing patterns can be challenging for any population, it can even more difficult for individuals with ASD due to the motorial and psychiatric barriers associated with their disability.

It was demonstrated that $75 \%$ of adolescents with ASD indicated that they would prefer to do something other than physical activity in their free time (STANISH et al., 2015), increasing their risk for a sedentary lifestyle. Despite inquiries showing the positive effects of physical activity on depression, little research has examined this relationship with mood variability, a core symptom associated with ASD. Thus, the current study examined the acute effects of an exercise regimen on depressive mood states and academic behaviors of university students with ASD.

Editora Unijuí - Revista Contexto \& Saúde - ISSN 2176-7114 - v. 21, n. 43, jul./set. 2021 


\section{METHOD}

\section{Participants}

Participants $(n=7)$ of this study were recruited from the Autism Individualized Mentoring and Support Services (AIMSS) at Fairmont State University. They were students of Fairmont State University from different programs age ranging between 18 and 24 years old. The AIMSS program supports students with Autism Spectrum Disorder (ASD) with an individualized plan to succeed in college that includes academic, social, and daily living support. To be accepted into the AIMSS program, a student must complete an application and provide documentation of a medical evaluation that examines psychological and intellectual functioning. Participants were sedentary, not engaged in other exercise activity. Prior to the start of the study, Institutional Review Board approval at Fairmont State University and informal consent was obtained from all participants.

\section{Instruments}

The American Heart Association/ American College of Sports Medicine, Health/Fitness Facility Pre-Participation Screening Questionnaire was given to the participants prior to the study. The purpose of the questionnaire was to assess participant's medical history, health risk, and current health status to determine if participants met the health standards required to take part in the study. However, one participant did not meet the required health standards and was removed from the study.

The Patient Health Questionnaire (PHQ-9 - Supplement Fig. 1), a 10-question self-report depression-mood assessment, was administered pre and post-exercise regimen to each participant. The close-ended PHQ-9 questionnaire was found to be most suitable for the individuals with ASD due to the tendency to over analyze information. The questionnaire format allows participants to focus on what was being asked, rather than implying other irrelevant factors, and was previously used in the ASD population (Fortuna et al., 2016). The questionnaire required participants to rate how often they had been bothered by mood variations related to depression (e.g., feeling down, feeling hopeless, low energy) using a 4-point Likert scale (3) nearly every day; (2) more than half the days; (1) several days; $(0)$ not at all.

A 10-question academic performance questionnaire was given by an instructor in the AIMSS program to measure the participant's academic performance pre and post exercise protocol. The questionnaire required instructors to rate participants on non-cognitive academic behaviors using a 5-point Likert scale (5 being strongly disagree and 1 being strongly agree). Examples of the questions were, student have room for improvement in their courses, students submit assignments on time, and student are open to suggestions made by theinstructor. This questionnaire was acquired from UK Medicine information (UKMi) and adapted for the study. 


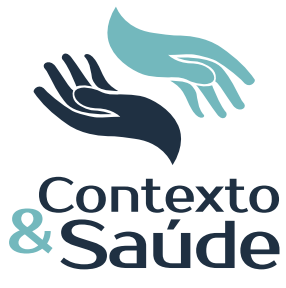

\section{Procedures}

Prior to the beginning of the study, participants were asked to identify exercises they found enjoyable and these were incorporated in the exercise regimen. Participants also completed a Health/Fitness Facility Pre-Participation Screening Questionnaire to screen for any previous health issues or risks that may be exacerbated by acute exercise. To obtain baseline academic data, the AIMSS instructor administered the academic performance questionnaire to participants before exercise program began.

Participants in the study completed one exercise sessions per week for three consecutive weeks under the supervision of an exercise science professional, the researcher. All exercise sessions were completed in a Fairmont State University gymnasium. On the first day of the study, the researcher provided a detailed explanation of the exercise protocol and a demonstration of each circuit training exercise. Before and after each exercise session, a Patient Health Questionnaire (PHQ-9) to measure depressive mood changes.

Exercise Program. Each session lasted approximately 45-minutes and included a warm-up and cool down involving 4 minutes of walking and dynamic stretching activities. The exercise regimen consisted of 12 circuit training stations that focused on a combination of strength and aerobic exercise activities. The circuit stations exercises included barbell triceps extensions, dumbbell bicep curls, lunges, line jumps, jump rope, agility ladder, wall balls, ropes, BOSU squats, step-ups, rows, poly spot staking planks, and easy bar shoulder press. Participants were instructed to complete as many repetitions as possible at each station for 60 -seconds. Additionally, participants were given 45 -seconds rest between each station before walking to the next. Participants would wait at the station until the researcher signaled to begin. The circuit training was up to ensure a limitation on barriers and maximize engagement. All participants were considered physically inactive prior to the exercise regimen. Therefore, the researcher chose exercises that would ensure a level of interest, adaptability, and performance success. Due to the level of physical inactivity the researcher provided instructional feedback if exercises were performed incorrectly.

Psychological Measurement. Prior to each exercise session a PHQ-9 Questionnaire was administered to each participant to measure self-reported depressive mood symptoms. The PHQ-9 Questionnaire was administered to participants again one hour after the exercise session in the classroom to assess the effects of the single bout of exercise on mood state.

Academic Measurement. An academic performance questionnaire was administered to the AIMSS instructor in the classroom prior to the $1^{\text {st }}$ exercise session to collect baseline data on non-cognitive academic behaviors. After three weeks, the same questionnaire was administered in the classroom after the last exercise session to determine the exercise effect on academic behaviors associated with academic performance. As lower the score better academic performance.

Editora Unijuí - Revista Contexto \& Saúde - ISSN 2176-7114 - v. 21, n. 43, jul./set. 2021 


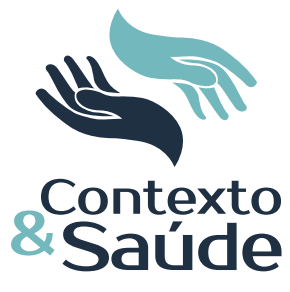

\section{Statistical Analysis}

Quantitative data derived from the PHQ-9 Questionnaire was added to give a total score of participant's level of depression severity. The lowest score a participant could receive was a one, which indicated the participant had a minimal depression; whereas the highest of twenty-seven would reveal severe depression. Data from the experiment were analyzed through different questionnaires and visual observation. A Dependent T-Test was taken to analyze whether if exercise will affect depression and academic performance. Along with a $p$-value of $<0.05$.

\section{RESULTS}

Participants were able to complete the questionnaire and the exercise sessions. Participant's mood in week one improved after the bout of exercise as shown in Fig 1. Participants were physically inactive prior to the exercise regimen, which more than likely caused the bout improvement in mood during week one. The acute improvement in mood; however, was not observed in the following weeks (Fig. 1). There was no difference in mood when comparing before and after exercise among weeks (Fig. 1). The results of the study showed there was no improvement in non-cognitive behaviors related to academic performance at the completion of the exercise program ( $p=0.11$, Fig 2).

\section{DISCUSSION}

The present study examined the acute effects of a single bout of exercise on mood states of university students with ASD. The findings revealed that a 60-minute bout of exercise improved mood in individuals with ASD after the first session, predominantly because the exercises protocol was new to the participants. However, after the effects of the exercise regimen on mood were diminished after the second and third sessions. While foundational research suggests that novel and varied tasks can lead to improved performance and mood for students with autism (DUNLAP; KOEGEL, 1980; DUNLAP, 1984), recent research on the use of novel technology in middle school physical education indicates that the motivational effect of novel materials or practices may be reduced over time for all students (MARTTINEN et al., 2019). The results of the present study align with these findings.

A second factor could have negatively impacted students' engagement and mood during the second and third sessions. Research conducted by Kaland, Smith and Mortensen (2008) found that individuals with autism may have difficulty with tasks that require sustained attention. The sustained attention needed to complete the exercise regimen in the 12 circuit training stations may have been increased during the final sessions because students needed to recall how to complete the exercises at each station from the initial demonstration in session one. As a result, reduced engagement due to task demands could have resulted in lower scores on the questionnaire. The authors do not discard the fact that participants were not happy with the end of the project, and that could have affected the effect of exercise on mood. In addition, the exercise program had no impact on the non-cognitive behaviors related to academic performance. 


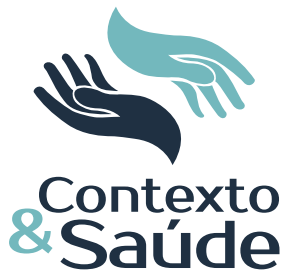

In the general population, depression is the most common psychiatric disorder, affecting approximately 121 million adults worldwide, and the fourth leading cause of disease burden (BLAKE, 2012). Although conventional treatments include psychotherapy and medication, it has become clear that physical activity may be protective against depressive mood states (HUME et al., 2011). Studies have suggested that exercise provides physiological and mental health benefits, including improvements in mood (SPRATT et al., 2018), and aerobic exercise has been shown to improve mood in different population (HEARING, 2016; MAMMEN; FAULKNER, 2013; TEYCHENNE; BALL; SALMON, 2008). Given that individuals with ASD have an increased risk of depression (SPRATT et al., 2018), exercise could be used as a therapeutic or treatment measure in the prevention of depression in individuals with ASD. Physical activity is especially important in specific populations, such as those with ASD due to their sedentary lifestyle, which puts them at risk for depressive symptoms.

Research supporting a relationship between physical activity, cognitive function, and academic performance has received much attention. It has been demonstrated that at least 30-minutes of aerobic exercise improves social skills, self-regulation, and behavioral skills, while reducing disruptive and stereotypical behaviors of adolescents in elementary settings (ORIEL et al., 2011). Although research supports that a single bout of exercise benefits cognitive function (DONNELLY et al., 2016), findings of this study demonstrated that the exercise program was insufficient in improving academic performance behaviors. Considering the cost of educating a student with ASD is significantly higher than that of a student without ASD (LAVELLE et al., 2014), it becomes important to uncover viable strategies that contribute to their academic performance.

Due to ASD characteristics providing education in a traditional environment is a challenge, therefore strategies to improve ASD student's wellbeing needs to be tested. Our novel findings demonstrated that a bout of exercise prior to class improved the mood of ASD university student and that might affect their performance during class (Fig. 3). On the other hand, longer periods of exercise, 3-weeks, was not enough to affect ASD university student's performance into the classroom based on the instructor evaluation. Long term exercise interventions might be used as a strategy to improve ASD academic success.

\section{ACKNOWLEDGEMENTS}

Authors acknowledge the Autism Individualized Mentoring and Support Services (AIMSS) at Fairmont State University for the use of their student program in this project.

\section{REFERENCES}

BAIO, J. et al. Prevalence of autism spectrum disorder among children aged 8 years autism and developmental disabilities monitoring network, 11 sites, United States. Morbidly and Mortality Weekly Report, 63, p. 1-24, 2014. DOl: http://dx.doi.org/10.15585/ mmwr.ss6706a1

Editora Unijuí - Revista Contexto \& Saúde - ISSN 2176-7114 - v. 21, n. 43, jul./set. 2021 


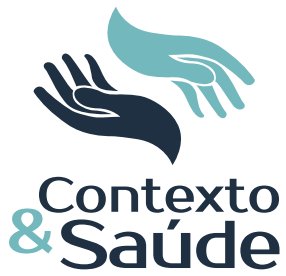

BAR, M. A cognitive neuroscience hypothesis of mood and depression. National Institutes of Health, 13(11), p. 456-463, 2009. DOI: https://doi.org/10.1016/j.tics.2009.08.009 BLAKE, H. Physical activity and exercise in the treatment of depression. Frontiers in Psychiatry, 3, p. 106, 2012. DOI: https://doi.org/10.3389/fpsyt.2012.00106

DONNELLY, J. E. et al. Physical activity, fitness, cognitive function, and academic achievement in children: A systematic review. Medicine and Science in Sports and Exercise, 48(6), p. 1.197-1.222, 2016. DOI: 10.1249/MSS.0000000000000901

DUNLAP, G. The influence of task variation and maintenance tasks on the learning and affect of autistic children. Journal of Experimental Child Psychology, 37(1), p. 41-64, 1984. DOI: https://doi.org/10.1016/0022-0965(84)90057-2

DUNLAP, G.; KOEGEL, R. Motivating autistic children through stimulus variation. Journal of Applied Behavior Analysis, 13(4), p. 619-627, 1980. DOI: https://doi.org/10.1901/ jaba.1980.13-619

GREEN, D. et al. Impairment in movement skills in children with autistic spectrum disorders. Developmental Medicine and Child Neurology, 51(4), p. 311-316, 2009. DOI: 10.1111/j.1469-8749.2008.03242.x

FARAS, H.; AL ATEEQI, N.; TIDMARSH, L. Autism spectrum disorder. Annals of Saudi Medicine, 30(4), p. 295-300, 2010. DOI: https://doi.org/10.4103/0256-4947.65261

FORTUNA, J. R. et al. Health conditions and functional status in adults with autism: A Cross sectional evaluation. Journal of General Internal Medicine, 31(1), p. 77-84, 2016. DOI: https://doi.org/10.1007/s11606-015-3509-x

HANSEN, C. J.; STEVENS, L. C.; COAST, J. R. Exercise duration and mood state: How much is enough to feel better? Health Psychology, 8(2), p. 267-275, 2011. DOI: https:// psycnet.apa.org/doi/10.1037/0278-6133.20.4.267

HEARING, C. M. et al. Physical exercise for treatment of mood disorders: A critical review. Current Behavioral Neuroscience Reports, 3(4), p. 350-359, 2016. DOI: https://doi. org/10.1007/s40473-016-0089-y

HUME, C. et al. Physical activity, sedentary behavior, and depressive symptoms among adolescents. Journal of Physical Activity and Health, 8(2), p. 152-156, 2011. DOI: https:// doi.org/10.1123/jpah.8.2.152

KALAND, N.; SMITH, L.; MORTENSEN, E. L. Brief report: Cognitive flexibility and focused attention in children and adolescents with asperger syndrome or high-functioning autism as measured on the computerized version of the wisconsin card sorting test. Journal of Autism \& Developmental Disorders, 38(6), p. 1.161-1.165, 2008. https://doi-org.ezproxy. fairmontstate.edu/10.1007/s10803-007-0474-1

LAVELLE, T. et al. Economic burden of childhood autism spectrum disorder. Official Journal of the American Academy of Pediatrics, 133(3), p. 520-529, 2014. DOI: https://doi. org/10.1542/peds.2013-0763

MAMMEN, G.; FAULKNER, G. Physical activity and the prevention of depression: A systematic review of prospective studies. American Journal of Preventive Medicine, 45(5), p. 649-657, 2013. DOI: https://doi.org/10.1016/j.amepre.2013.08.001

MANNAN, M. et al. Prospective Associations between Depression and Obesity for Adolescent Males and Females - A Systematic Review and Meta-Analysis of Longitudinal Studies. PloS one, 11(6), e0157240, 2016. DOI: https://doi.org/10.1371/journal. pone.0157240

MARTTINEN, R. et al. Students' perceptions of technology integration during the F.I.T. unit. Research Quarterly for Exercise \& Sport, 90(2), p. 206-216, 2019. DOI: 10.1080/02701367.2019.1578328

ORIEL, K. N. et al. The effects of aerobic exercise on academic engagement in young children with autism spectrum disorder. Pediatric Physical Therapy, 23(2), p. 187-193, 2011. DOI: 10.1097/PEP.0b013e318218f149

PAPASAVVAS, T. et al. Depression symptom severity and cardiorespiratory fitness in healthy and depressed adults: a systematic review and meta-analysis. Sports Medicine, 46, p. 219-230, 2016. DOI: 10.1007/s40279-015-0409-5

Editora Unijuí - Revista Contexto \& Saúde - ISSN 2176-7114 - v. 21, n. 43, jul./set. 2021 
SCHUCH, F. et al. Physical activity and sedentary behavior in people with major depressive disorder: a systematic review and meta-analysis. J Affect Disord, 210, p. 139-150, 2017. DOI: 10.1016/j.jad.2016.10.050

SPRATT, E. et al. Translating benefits of exercise on depression for youth with autism spectrum disorder and neurodevelopmental disorders. Journal of Psychology and Psychiatry, 2, p. 109, 2018.

STANISH, H. et al. Enjoyment, barriers, and beliefs about physical activity among adolescents with and without autism spectrum disorder. Adapted Physical Activity Quarterly, 32(4), p. 302-317, 2015. DOI: https://doi.org/10.1123/APAQ.2015-0038

STRANG, J. F. et al. Depression and anxiety symptoms in children and adolescents with autism spectrum disorder without intellectual disabilities. National Institutes of Health, 6(1), P. 406-412, 2012. DOI: https://doi.org/10.1016/j.rasd.2011.06.015

STERLING, L. et al. Characteristics associated with presence of depressive symptoms in adults with autism spectrum disorder. Journal of Autism Spectrum Disorders, 38, p. 1.011-1.018, 2007. DOI: https://doi.org/10.1007/s10803-007-0477-y

TOSCANO, C. V.; CARVALHO, H. M.; FERREIRA, J. P. Exercise effects for children with autism spectrum disorder: Metabolic health, autistic traits, and quality of life. Perceptual and Motor Skills, 125(1), p. 126-146, 2017. DOI: https://doi.or$\mathrm{g} / 10.1177 \% 2 \mathrm{F0031512517743823}$

TEYCHENNE, M.; BALL, K.; SALMON, J. Associations between physical activity and depressive symptoms in women. International Journal of Behavioral Nutrition and Physical Activity, 5, P. 27, 2008. DOI: https://doi.org/10.1186/1479-5868-5-27

$\mathrm{WEI}$, J. et al. Science, technology, engineering, and mathematics (STEM) participation among college students with an autism spectrum disorder. Journal of Autism and Developmental Disorders, 43, p. 1.539-1.546, 2013. DOI: 10.1007/s10803-012-1700-z 
Figure 1 - Mood Pre- and Post- exercise session determined by a PHQ-9 questionnaire over a period of 3 weeks. Data is presented as mean $\pm \mathrm{SEM}, * \mathrm{P}<0.05$ compared to Pre-Exercise

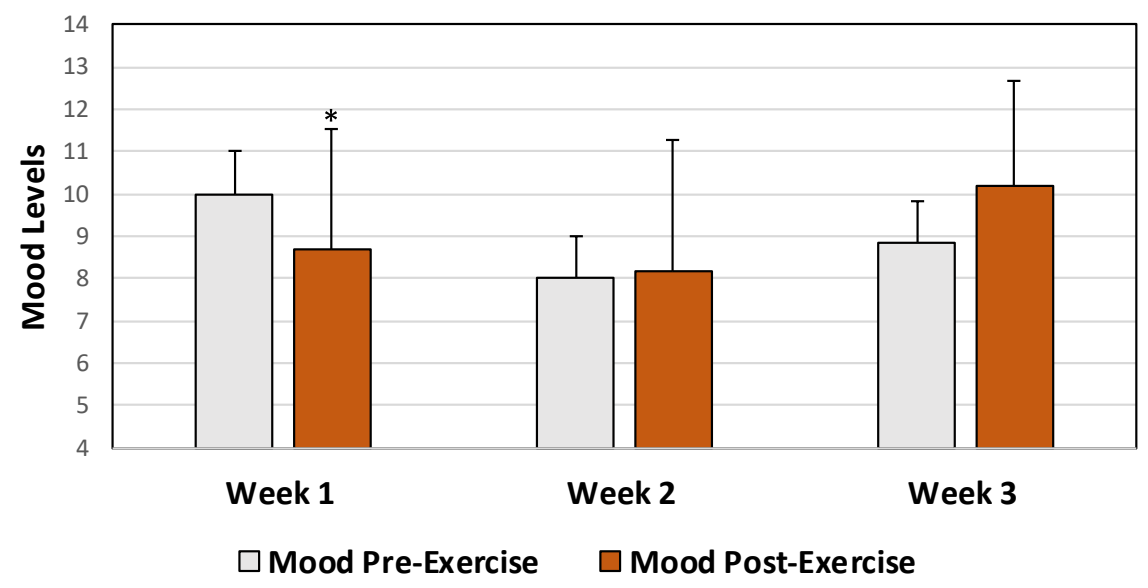

Source: Elaborated by the authors.

Figure 2 - Academic Performance Scores Pre- and Post- exercise intervention determined by a questionnaire answered by the class instructor. Data

is presented as mean \pm SEM

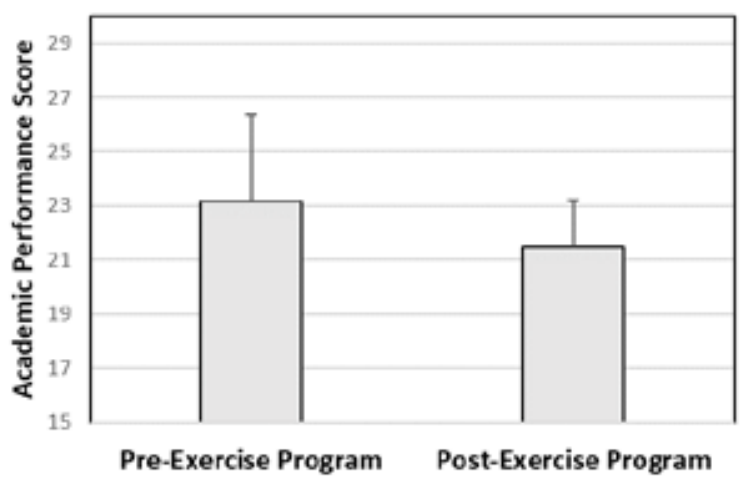

Source: Elaborated by the authors.

Figure 3 - Suggested outcome of acute exercise on academic performance for the ASD (Autism spectrum disorders) population

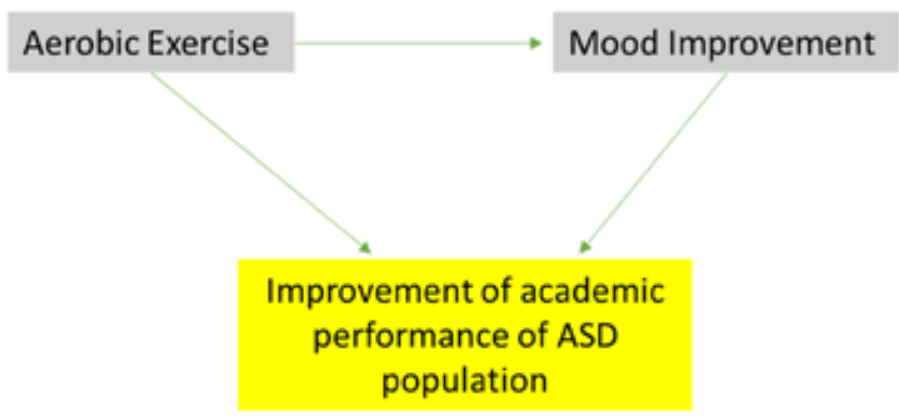

Source: Elaborated by the authors. 